\title{
Lippes loop in the retroperitoneal space
}

\author{
Anuruddha M Abeygunasekera ${ }^{1}$, Kapila Vithanachchi ${ }^{2}$, Ruwan Jayasinghe ${ }^{3}$, Tushara \\ Chamintha $^{3}$ \\ ${ }^{1}$ Urological Surgeon, ${ }^{2}$ Registrar in Obstetrics \& Gynaecology, ${ }^{3}$ Senior Houser Officer in Urology, \\ Urology Unit, Teaching Hospital, Karapitiya, Galle.
}

\section{Case Report}

A63 year-old mother of six children was found to be having a left renal stone on ultrasonography. The IVU showed a $2 \mathrm{~cm}$ stone in the left renal pelvis. In addition it revealed a Lippes loop in the region of the left sacroiliac joint, closely related to the left ureter (Figure 1). Twenty one years ago she has had a Lippes loop inserted (after her third child) which was never removed. Since then she had borne three more children but the IUD (Intrauterine device) was never looked for.

Left pyelolithotomy was performed via the transcostal approach and exploration of the retroperitoneal space revealed the Lippes loop located retroperitoneally closely related to the ureter. It was removed with ease (Figure 2).

\section{Discussion}

Transmigration if the IUDs from the uterine to the pelvic cavity is well known. Most of the migrated IUDs are located within the abdominal cavity and found in the conglomerated mesh bordered by intestines and omentum [1]. Some migrate into the bladder and appendix causing stones and appendicitis, respectively [2, 3]. Rarely IUDs have been found to be embedded in the parametrial tissue of the broad ligament [4]. However, extraperitoneal migration of Lippes loop into retroperitoneal tissue is very rare.

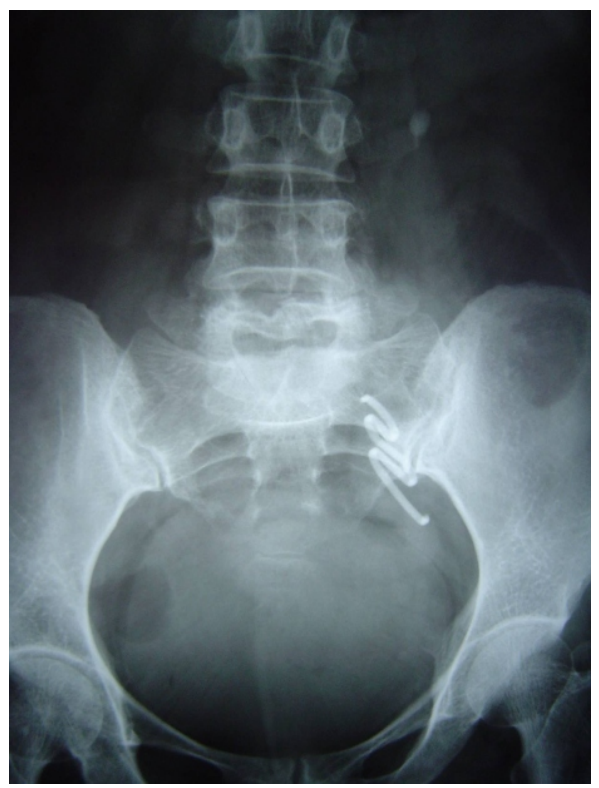

Figure 1 - IVU showing the Lippes loop 


\section{Case Reports}

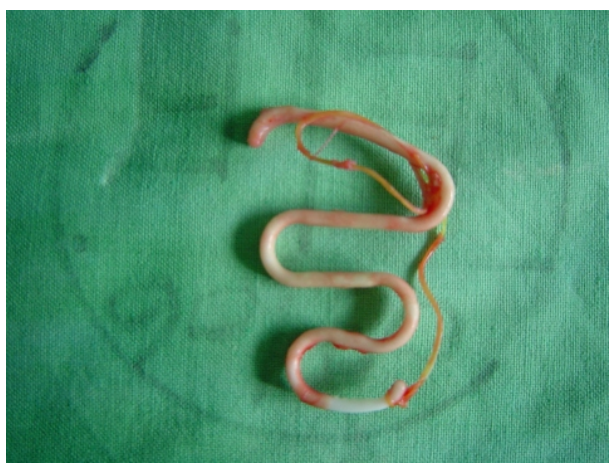

Figure 2 - Lippes loop after removal

Pregnancy should raise suspicion of improper placement, transmigration or expulsion of the IUD [5]. If the lost IUD is not found in the placenta and membranes at the time of delivery, imaging of the abdomen and pelvis must be done to locate it. When intraperitoneal, laparoscopic removal of the IUD is considered the first choice of therapy [1]. However, open surgery may be necessary in some [6].

\section{References}

1. Demir SC, Cetin MT, Ucunsak IF, Atay Y, Toksoz L, Kadayitei O. Removal of intra-abdominal intrauterine device by laparoscopy. European Journal of Contraception and Reproductory Health Care 2002; $7: 20-3$

2. Abeygunasekera AM, Nirupika $H$, Bulegoda $H$. Endoscopic surgery without endoscopic instruments. Sri Lanka Journal of Urology 2002; 3: 18

3. Seira I. Appendicitis caused by an intrauterine contraceptive device. British Journal of Surgery 1986; 73: $927-8$

4. Mallik MK. Lippes loop in the broad ligament. Journal of Obstetrics and Gynaecology of India 1968;18: 336-7

5. Senanayaka HM, Harshini Fernando. An intrauterine device in the bladder mimicking urinary tract infection. Ceylon Medical Journal 2002; 47: 28

6. Eckford SD, Persal RA, Brenester SF, Gingell JC. Intravesical foreign bodies: Five year review. British Journal of Urology 1992; 69: 41-5 